Editorial

\title{
Computers \& Graphics journal special section on Cultural Heritage
}

\section{Introduction}

An increasing number of Cultural Heritage professionals are using Computer Graphics technology to unlock and document the secrets of humanity's legacy. Earlier this year, a recent special issue of this journal published some of the important results from the intersection of these two fields [1]. The level of interest and the quality of submissions was such that an additional special section is necessary to showcase three further exciting results.

Andujar et al. [2] discuss the design of the user interface for the virtual inspection of the entrance of the Ripoll Monastery in Spain. The authors analyze the requirements from museum curators and discuss the main interface design decisions. Results of a user study comparing the proposed user interface with alternative approaches are provided together with a discussion of its benefits to the Cultural Heritage Community.

Adán et al. [3] propose a semi-automatic approach for the reconstruction of archeological pieces through the integration of a set of only a few segments of the original piece. This highly complex problem is tackled by considering hybrid human/computer strategies. Hypotheses, models and integration solutions originating from both humans and computers are continuously updated until an agreement is reached. This restoration approach has been tested on a set of ancient fractured pieces belonging to the remains of Roman sculptures at the well known Mérida site.

Finally, Ritz et al. [4] present a novel 3D geometry acquisition technique at high resolution based on structured light reconstruction with a low-cost projector-camera system. The proposed setup allows reconstruction of the finest details of small cultural heritage objects and enables accurate height field measurements which can be used as input to physically based renderers.

The cooperation between the diverse fields of cultural heritage and computer graphics is maturing. Researchers and practitioners in both fields now regularly work closely together. Many more high quality publications are expected as the synergies between the two disciplines are realized in future collaborations.

\section{References}

[1] Chalmers Alan, Mudge Mark, Santos Luís Paulo. Special Section on Cultural Heritage. Computers and Graphics 2011;35(4).

[2] Andujar Carlos, Chica Antonio, Brunet Pere. User-interface design for the Ripoll monastery exhibition at the national art museum of Catalonia. Computers and Graphics 2012;36(1):28-37.

[3] Adán Antonio, Salamanca Santiago, Merchán Pilar. A hybrid human-computer approach for recovering incomplete cultural heritage pieces. Computers and Graphics 2012;36(1):1-15.

[4] Ritz Martin, Langguth Fabian, Scholz Manuel, Goesele Michael, Stork André High resolution acquisition of detailed surfaces with lens-shifted structured light. Computers and Graphics 2012;36(1):16-27.

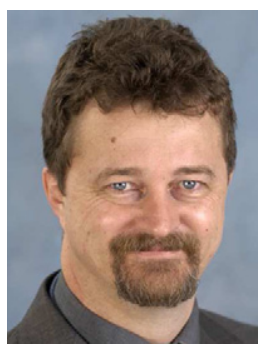

Alan Chalmers is Professor of Visualisation in the International Digital Laboratory, WMG, at the University of Warwick. He has published over 200 papers in journals and international conferences on realistic computer graphics, parallel processing, multisensory perception and virtual archaeology. He is Honorary President of Afrigraph and a former Vice President of ACM SIGGRAPH. In addition, he is Founder and Innovation Director of the spinout company, goHDR, which is developing software to facilitate the wide spread adoption of high dynamic range (HDR) imaging technology. His research is working towards achieving Real Virtuality: high-fidelity, multi-sensory virtual environments, including developing "digital taste".

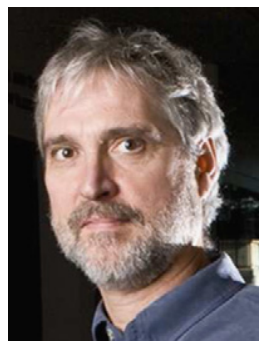

Mark Mudge is President and co-founder of Cultural Heritage Imaging (CHI), a public charity and California non-profit corporation, incorporated in 2002. Mark has BA in Philosophy from New College of Florida (1979). He has worked as a professional bronze sculptor and has been involved in photography and 3D imaging for over 20 years. He is a co-inventor, with Tom Malzbender, of the computational photography technique, Highlight Reflectance Transformation Imaging. He has published twelve articles and book chapters related to imaging cultural heritage materials and serves on several international committees, including The International Council of Museums' (ICOM) Documentation Committee (CIDOC).

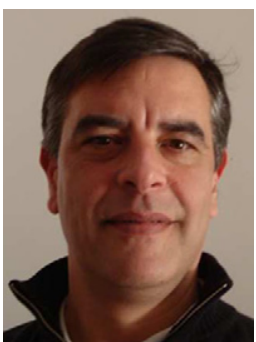

Luis Paulo Santos is an Auxiliar Professor at the Department of Informatics, Universidade do Minho, Portugal. His research interests are in interactive high fidelity rendering and parallel processing. He received his $\mathrm{PhD}$ in 2001 from Universidade do Minho in Scheduling under Conditions of Uncertainty. Luis Paulo published several papers on both computer graphics and parallel processing on international conferences and journals. He has been a member of several international program committees, acted as program cochair of the 2007 EGPGV symposium and EuroPar 2005 conference and organized EGPGV 2006, VAST 2008 and VSGames 2010 in Braga, Portugal. He manages several nationally funded graphics $R \& D$ projects and participates in several European projects with both academia and industry. He is a member of the Direction Board of the Portuguese chapter of Eurographics since 2008.

Alan Chalmers, Mark Mudge, Luis Paulo Santos* Departamento de Informatica, Universidade do Minho, Campus de Gualtar, 4710-054 Braga, Portugal E-mail addresses: Alan.Chalmers@warwick.ac.uk (A. Chalmers), mark@c-h-i.org (M. Mudge),psantos@di.uminho.pt (L.P. Santos)

Received 16 November 2011

\footnotetext{
* Corresponding author. Tel.: +351253 604439; fax: +351253604471.
} 